\title{
Testing the Indirect Effect of Type 1 Diabetes on Life Satisfaction Through Self-Compassion and Self-Coldness
}

\author{
Edyta Charzyńska $^{1}$ (D) Dagna Kocur ${ }^{1}$ (D) $\cdot$ Sara Działach $^{1} \cdot$ Rachel E. Brenner $^{2}$ (D)
}

Published online: 16 July 2020

(C) The Author(s) 2020

\begin{abstract}
Objectives Diabetes is a chronic disease that markedly affects the daily life of individuals and lowers subjective well-being. Selfcompassion, or treating oneself with kindness and acceptance during challenging circumstances, may improve subjective wellbeing among people with diabetes. In the current study, we explored the relationships between duration of diabetes, positive and negative components of self-compassion (i.e., self-compassion and self-coldness), and life satisfaction.

Methods The sample consisted of 112 persons with type 1 diabetes. A Self-Compassion Scale and Satisfaction with Life Scale were used.

Results A parallel multiple mediation model revealed that diabetes duration was related to lower self-coldness but not to selfcompassion. Both self-coldness and self-compassion strongly correlated with life satisfaction. Diabetes duration demonstrated a significant indirect effect on life satisfaction through self-coldness $(b=0.08,95 \%$ CI $[0.01,0.16])$, but not through selfcompassion $(b=0.00,95 \% \mathrm{CI}[-0.06,0.06])$.

Conclusions The study suggests the need to examine the positive and negative components of the Self-Compassion Scale separately when studying well-being of persons with type 1 diabetes, as well as to prepare tailored self-compassion and selfcoldness interventions that can be adjusted for people with varying diabetes durations.
\end{abstract}

Keywords Type 1 diabetes $\cdot$ Duration of diabetes $\cdot$ Self-compassion $\cdot$ Self-coldness $\cdot$ Life satisfaction $\cdot$ Well-being

Type 1 diabetes (T1D), also called insulin-dependent diabetes or juvenile diabetes, is a chronic and unremitting disease that comprises approximately 5 to $10 \%$ of all diabetes cases (Daneman 2006). In T1D, the immune system attacks the insulin-producing $\beta$ cells in the pancreas, culminating in absolute insulin deficiency. The onset of T1D can occur at any age, but it is seen mostly before 30 years of age (Van Tilburg et al. 2001).

T1D places a significant burden on individuals and their families, affecting emotional, mental, occupational, and social functioning (Lloyd and Orchard 1999; Ventura et al. 2019). Living with T1D demands daily self-management that includes strict adherence to a treatment regimen of

Edyta Charzyńska

edyta.charzynska@us.edu.pl

1 Faculty of Social Sciences, University of Silesia in Katowice, ul. Grażyńskiego 53, 40-126 Katowice, Poland

2 Department of Educational \& Counseling Psychology, University at Albany-State University of New York, Catskill 223, 1400 Washington St, Albany, NY 12222, USA administering insulin multiple times a day via injections or an insulin pump, regularly monitoring blood glucose levels, counting carbohydrates, following a healthy diet, exercising regularly, and managing ongoing medical care (Daneman 2006). Not adhering to the treatment regimen may lead to serious microvascular and macrovascular complications, and even death (World Health Organization [WHO] 2016).

Not surprisingly, T1D has a detrimental effect on emotional well-being, evoking feelings of fear, blame, guilt, and shame (Friis et al. 2016), which can lead to depression and anxiety (Roy and Lloyd 2012). People with diabetes report lower life satisfaction than in the general population (Connell et al. 1990; Holmes-Truscott et al. 2016) and this decreased subjective wellbeing is somewhat more common among patients with longer diabetes duration (Ahola et al. 2010; Lloyd and Orchard 1999). In a study of 1000 diabetic persons, those with longer diabetes durations were more depressed, and had lower levels of energy, positive well-being, and general well-being (Petterson et al. 1998). This makes sense because life satisfaction results from congruence between a person's perceived life circumstances with their own set of standards in a longer time perspective (Pavot and Diener 2008). Longer duration of diabetes is associated with the 
higher rates of serious complications and diabetes-related comorbidities (Gebremedhin et al. 2019; Gorst et al. 2015); thus, the longer a person has diabetes, the more they experience the longterm impact of TD1 on their desired goals, aspirations, and livelihood.

It has been well documented that satisfaction with life contributes to effective self-management and thus better clinical outcomes in people with diabetes (American Diabetes Association [ADA] 2019b; Stahl-Pehe et al. 2017). Therefore, the ADA (2019b) calls for T1D patient care to extend beyond medical outcomes to quality of life and subjective well-being. In light of the above facts, there is a necessity to seek psychological factors that may help patients with T1D lead more satisfying lives (Pavot and Diener 2008). Selfcompassion is a promising candidate given its healthpromoting effects noted in previous studies (Neff and Germer 2013; Sirois et al. 2015).

Introduced to the scientific literature by Neff (2003a), selfcompassion involves relating to oneself with kindness, care, and acceptance in times of failure and difficulty. Selfcompassion consists of three components on bipolar ends: (1) being kind, caring, and understanding with oneself (selfkindness) rather than being harsh and judgmental (self-judgment); (2) recognizing that all humans are imperfect and that all people make mistakes and have serious life difficulties (common humanity) rather than feeling isolated from other people as a result of one's perceived imperfection (isolation); and (3) taking a balanced perspective of one's painful experiences (mindfulness) rather than becoming fully absorbed by one's problems and embroiled by one's own negative emotional states (over-identification; Neff 2016). There is substantial evidence that self-compassion improves mental health and well-being by helping people respond to stressful events or feelings of inadequacy in a healthy way, providing greater emotional resilience, facilitating goal setting and goal achievement, and promoting positive health behaviors (Sirois et al. 2015; Zessin et al. 2015).

A growing number of studies suggest self-compassion is beneficial in diabetes treatment. For instance, in a study of 310 adults with T1D or type 2 diabetes (T2D), self-compassion was associated with better psychological well-being, improved self-management behavior, and more optimal hemoglobin Alc (HbAlc) levels (Ferrari et al. 2017). Findings of a large study $(N=1907)$ of adults with TD1 or TD2 supported these results (Ventura et al. 2019). Specifically, selfcompassion was associated with behavioral (i.e., healthy eating and physical activity), clinical (i.e., better HbAlc results), and emotional (i.e., fewer depressive and anxiety symptoms, and lower diabetes distress) outcomes. Similarly, Friis et al. (2015b) found that self-compassion was negatively related to diabetes distress and depression among patients with T1D and T2D. Moreover, self-compassion buffered the effect of high diabetes distress on suboptimal $\mathrm{HbAlc}$.
Most studies measure self-compassion using the SelfCompassion Scale (SCS; Neff 2003b). This 26-item research tool consists of 6 subscales, or 3 bipolar pairs consistent with theoretical foundations: self-kindness versus self-judgment, common humanity versus isolation, and mindfulness versus over-identification. Although the SCS was originally proposed as a one-factor measure, in recent years, scholars have debated whether the SCS is actually a two-factor measure. A growing number of studies have demonstrated that the three positive scales and three negative scales of the SCS in fact create two separate, superordinate factors (named selfcompassion and self-coldness or self-criticism, respectively; Brenner et al. 2017; López et al. 2015) that are theoretically distinct, have unique associations with well-being and distress, and respond differently to interventions (Brenner et al. 2018; Eriksson et al. 2018). In diabetes research, one study considered the distinction between self-compassion and selfcoldness (Kane et al. 2018); in a sample of adults with T2D, baseline self-coldness significantly predicted diabetes distress over 3 months. By contrast, self-compassion was not independently correlated with diabetes distress, neither crosssectionally nor longitudinally (Kane et al. 2018).

The purpose of the current study was to examine the relationships between duration of diabetes, self-compassion, selfcoldness, and satisfaction with life among people with T1D.

Consistent with previous research, we expected a negative direct effect of duration of diabetes on life satisfaction (Ahola et al. 2010; Petterson et al. 1998). However, with longer duration of disease - as people become used to the routine and self-management of TD1 - it may become easier to respond to themselves and their T1D more compassionately (Sirois et al. 2015) and less coldly. Thus, there may also be positive indirect effects of diabetes duration on life satisfaction through self-compassion and self-coldness. Accordingly, we hypothesized that diabetes duration would be positively related to selfcompassion and negatively to self-coldness; in turn, selfcompassion and self-coldness would be positively and negatively associated with life satisfaction, respectively. In other words, we hypothesized two positive indirect effects of diabetes duration on life satisfaction through self-compassion and self-coldness, which are in the opposite direction of the hypothesized direct effect. This concept of inconsistent mediation (MacKinnon et al. 2007) has been observed in the social science literature (Vermeulen-Smit et al. 2014).

\section{Method}

\section{Participants}

The sample consisted of 112 adults (80.4\% women and $19.6 \%$ men) with T1D. The mean age of the participants was 28.29 years $(S D=7.6)$. Approximately two-thirds $(n=73)$ 
of the participants were in an intimate relationship, whereas 38 of them were single; 1 person did not indicate relationship status. The mean duration of diabetes was 13.75 years $(S D=8.78)$. HbAlc exceeded the threshold value of $7 \%$ (ADA 2019a) for 60 participants $(53.6 \%)$; for the remaining participants, the counts were normal (i.e., $<7 \%$ ).

\section{Procedures}

A web-based survey was administered from February to August 2018. The information about the research was placed in Polish-speaking Facebook groups focused on promoting diabetes care and sharing personal experiences with diabetes management. Moreover, a request for participation was sent to people who described in their Instagram accounts that they had diabetes. The participants were informed about the aims of the study and its procedure and were assured about the voluntary participation and anonymity. Informed consent was obtained online from each participant.

\section{Measures}

Self-Compassion Scale (SCS) The SCS (Neff 2003b) is a 26item scale that assesses positive (i.e., compassionate) and negative (i.e., uncompassionate) ways of self-responding during times of adversity. Each item is measured using a 5-point Likert scale, on which 1 means "almost never," and 5 means "almost always." The current study used the Polish version of the SCS. Examination of the factor structure and model-based reliability of the Polish SCS supported the use of the SCS as a two-factor measure of self-compassion and self-coldness rather than one-factor measure (Fopka-Kowalczyk et al., manuscript in preparation). Similarly, self-compassion and selfcoldness have demonstrated unique patterns of correlations with positive (e.g., humor, emotional support) and negative (e.g., disengagement, substance use) coping strategies (Fopka-Kowalczyk et al., manuscript in preparation), which is consistent with research that used the SCS to examine its relationships with positive and negative outcomes (e.g., Brenner et al. 2018; see also Muris et al. 2019). Overall, the results of the Polish validation indicated that the SCS is a reliable and valid tool, which can be used to measure selfcompassionate and uncompassionate ways of selfresponding during times of adversity.

In the current study, self-compassion was calculated as a sum of three components of compassionate self-responding and the latter as a sum of three components of uncompassionate self-responding. Cronbach's alphas ranged from 0.72 ("mindfulness") to 0.86 ("self-kindness") for the SCS scales. Self-compassion and self-coldness indices yielded an internal consistency estimate of 0.89 and 0.85 , respectively.
Satisfaction with Life Scale (SWLS) We used a Polish adaptation (Juczyński 2001) of the SWLS (Diener et al. 1985) to assess satisfaction with the respondent's life as a whole. SWLS is one of the most widely used measures of the cognitive-judgmental component of subjective well-being in both research and clinical settings (Pavot and Diener 2008). Participants indicated the extent to which 5 items of the SWLS reflected how they perceived their lives, using a 7 point Likert scale (1 = "strongly disagree," $7=$ "strongly agree"). The level of life satisfaction was calculated by summing up all the responses. Cronbach's alpha coefficient for SWLS in the current study was 0.88 .

Sociodemographics and Diabetes-Related Measures The sociodemographic characteristics of the participants were measured with single items. As for diabetes-related characteristics, participants were asked about the duration of diabetes and their latest results for the $\mathrm{HbA} 1 \mathrm{c}$ test.

\section{Data Analyses}

Sample size was determined in accordance with the recommendations of Fritz and Mackinnon (2007) for achieving adequate power when testing for mediation. We selected a medium effect size based on prior research and theoretical premises (Sirois et al. 2015; Zessin et al. 2015). For a mediation analysis using a bias-corrected bootstrapping method, a sample size of 71 would be required to detect a medium mediation effect with $80 \%$ power (Fritz and Mackinnon 2007). Therefore, the current sample size $(N=112)$ was sufficiently powered.

In the first step of analysis, we examined patterns of missing data using the Little's Missing Completely at Random test (Little 1988) to decide whether and how to impute the missing values. Then, we calculated descriptive statistics along with bivariate correlations for the study variables. Calculations were performed using IBM SPSS Statistics version 25.0 (IBM Corp. 2017).

In the next step, we tested a parallel multiple mediation model using the PROCESS macro for SPSS (Model 4; Hayes 2013). In this model, the specific indirect effects of potential mediators are tested simultaneously, without the assumption of causal relationships between them (Preacher and Hayes 2008). To test indirect effects, we computed 10,000 bootstrapping subsamples and used a 95\% bias-corrected confidence interval (MacKinnon et al. 2004; Shrout and Bolger 2002). Bootstrap methods demonstrate high statistical power and address the nonnormality of the indirect effect sampling distribution (MacKinnon et al. 2004). An indirect effect was considered significant if the particular $95 \%$ bootstrap confidence interval did not include the value of 0 . Based on the theoretical premises, gender and the self-reported $\mathrm{HbA} 1 \mathrm{c}$ level were introduced to the mediation model as control variables (Sparring et al. 2013; Tanenbaum et al. 2018). 


\section{Results}

The percentage of missing values was $1.04 \%$. Little's test indicated that the missing cases followed the pattern of missing completely at random $\left(\chi^{2}(4)=3.49 ; p=0.48\right)$. We then performed a single imputation by the expectationmaximization algorithm (Dempster et al. 1977). For all the calculations, we used the Missing Value Analysis Module in SPSS version 25.0 (IBM Corp 2017).

Table 1 presents means, standard deviations, and bivariate correlations for the study variables. Following the interpretation of the SWLS scores suggested by Diener (2006), 27.7\% of the patients were dissatisfied or extremely dissatisfied with their lives; $18.8 \%$ were slightly below the average in life satisfaction; $33.0 \%$ had an average level of life satisfaction; and $20.5 \%$ were satisfied or highly satisfied with their lives. Life satisfaction was strongly correlated with both self-compassion and self-coldness. Diabetes duration was negatively correlated with self-coldness but was not significantly correlated with self-compassion or life satisfaction.

The multiple mediation model results are presented in Fig. 1 and Table 2. As predicted, duration of diabetes was associated with lower self-coldness $(b=-0.25, p=0.017 ; \beta=-0.23)$, which, in turn, was linked to lower life satisfaction $(b=-0.31$, $p<0.001 ; \beta=-0.45)$. Diabetes duration did not demonstrate a significant relationship with self-compassion $(p=0.96)$ or a direct effect on life satisfaction $(p=0.63)$. Bootstrapping results indicated a significant indirect effect of diabetes duration on life satisfaction through self-coldness $(b=0.08,95 \%$ CI $[0.01$, $0.16])$. Conversely, the indirect effect via self-compassion was not significant $(b=0.00,95 \%$ CI $[-0.06,0.06])$. The total effect of diabetes duration on life satisfaction was not significant $(b=$ $0.05, p=0.50$ ). The model accounted for $47 \%$ of the explained variance in life satisfaction.

\section{Discussion}

\section{Role of Self-Coldness Versus Self-Compassion in Life Satisfaction}

This study examined associations between duration of illness, self-compassion, self-coldness, and life satisfaction among persons with T1D. The most important finding of our study is that diabetes duration demonstrated an indirect effect on life satisfaction through self-coldness. This effect may be explained by a time-related increase in patients' knowledge of diabetes and a better understanding of its causes, course, and treatment regimen (Cunningham et al. 2018; Kueh et al. 2015). With diabetes duration, those with T1D may gain and/or internalize awareness that they are not responsible for the occurrence of the disease. They also may gain a greater understanding that diabetes does not necessarily mean either being overwhelmed with fears of not meeting glycemic targets or separating oneself from other people due to diabetes. The recognition of these facts may alleviate patients' feelings of self-criticism, sense of isolation, and over-identification with negative feelings related to diabetes, thereby improving their satisfaction with life (see Friis et al. 2015a).

Unexpectedly, the relationship between diabetes duration and life satisfaction was non-significant. This result might be due to our specific sample consisting of somewhat young individuals diagnosed with diabetes for a relatively short period of time. While it is well documented that diabetes complications increase in severity and reduce quality of life and well-being over time (Gebremedhin et al. 2019; Gorst et al. 2015), complications typically develop 15-20 years after onset (Alemzadeh and Ali 2011; Altınok et al. 2016). Future studies should examine the relationship between diabetes duration and life satisfaction across samples of patients with more diversified duration of disease.

In contrast with the findings concerning self-coldness, duration of diabetes was not significantly related to self-compassion. As such, the indirect effect of diabetes duration on life satisfaction through self-compassion was also not significant. These results provide support for studies advocating for a separate analysis of self-compassion and self-coldness (Brenner et al. 2017; Muris and Petrocchi 2017). Moreover, in this context, it is useful to recall a metaphor used by Gable and Haidt (2005) that compares traditional psychology and positive psychology: "[P]sychology was said to be learning how to bring people up from negative eight to zero but not as good at understanding how people rise from zero to positive eight" (p. 103). Likewise, our study suggests that the timerelated decrease in self-coldness brings people with T1D from "negative eight to zero." However, in light of the findings, it seems dubious that "rising from zero to positive eight" (i.e., increasing self-compassion) may occur spontaneously over
Table 1 Means, standard deviations, and correlations between study variables

\begin{tabular}{|c|c|c|c|c|c|c|c|}
\hline Variables & $M$ & $S D$ & Range & (1) & (2) & (3) & (4) \\
\hline 1. Duration of diabetes (years) & 13.75 & 8.78 & $0.5-46$ & - & & & \\
\hline 2. Self-compassion & 34.81 & 9.41 & $13-65$ & 0.01 & - & & \\
\hline 3. Self-coldness & 41.96 & 9.72 & $13-65$ & $-0.23 *$ & $-0.22 *$ & - & \\
\hline 4. Life satisfaction & 19.21 & 6.70 & $7-35$ & 0.08 & $0.53 * * *$ & $-0.54 * * *$ & - \\
\hline
\end{tabular}

$M$, mean; $S D$, standard deviation. $* p<0.05, * * * p<0.001 . N=112$ 


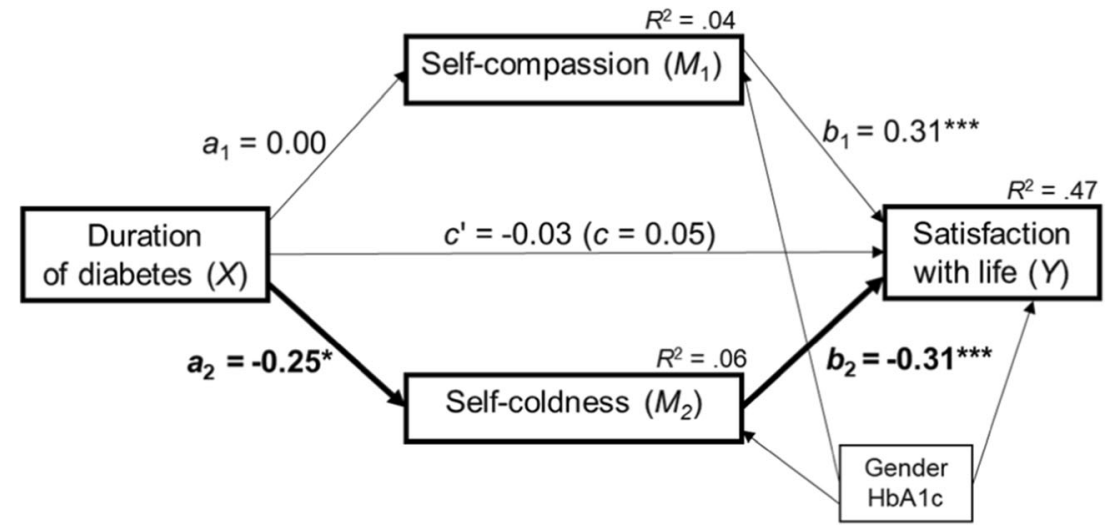

Fig. 1 Parallel multiple mediation model for satisfaction with life. $* p<0.05, * * * p<0.001 . X=$ independent variable; $M=$ mediating variable; $Y=$ dependent variable; path $a=$ effect of $X$ on $M$; path $b=$ effect of $M$ on $Y$; path $c^{\prime}=$ direct effect (the effect of $X$ on $Y$ adjusted for $M$ ); path $c=$ total effect (the sum of direct and indirect effects; $c^{\prime}+a b$ ). The regression coefficients were displayed in unstandardized form.

time in this group. It is more likely that the development of self-compassion requires additional emotional and cognitive efforts to initiate considerable changes in one's attitude toward self.

The results of our study have important practical implications concerning the preparation of self-compassion trainings for patients with T1D. Self-compassion is considered to be a trainable resource that can be fostered with appropriate interventions (Neff and Germer 2013). Indeed, a randomized control trial involving an 8-week mindful self-compassion (MSC) intervention for patients with diabetes increased selfcompassion; and reduced depression, diabetes distress, and $\mathrm{HbA1c}$ in the experimental group only, with results maintained at 3-month follow-up (Friis et al. 2016). Our study findings suggest that the content of self-compassion interventions should be adjusted to diabetes duration. More specifically, for patients with longer diabetes duration, therapeutic interventions aimed at directly promoting self-kindness, common humanity, and mindfulness may be particularly fruitful. By contrast, patients with a short duration of diabetes may primarily need interventions aimed at reducing the levels of self-coldness components. The latter suggestion is roughly consistent with the opinion of Friis et al. (2015a) who consider
Significant indirect effect pathways are presented in bold. For legibility, the regression coefficients for two control variables (i.e., gender and HbA1c level) were omitted. Control variables only demonstrated one significant relationship: exceeding the HbAlc threshold value of $7 \%$ was associated with lower self-compassion $(b=-3.62 ; p=0.049)$

reducing negative self-judgment to be crucial for improving the life satisfaction of persons with diabetes.

\section{Limitations and Future Research}

Several limitations of our study should be considered and lend recommendations for future research. Although our sample size exceeded the minimum requirement for our study analyses, the number of participants was relatively small. The majority of participants were women, and we recruited our sample through social networking sites, which may limit the generalizability of our results. As such, future research should examine this model among more diverse samples. Another limitation is that we did not control for comorbidity in our analyses. Instead, we focused on two control variables, gender and $\mathrm{HbAlc}$, based on empirical findings that being female (Graue et al. 2003; Sparring et al. 2013) and having poor glycemic control (as measured by HbA1c; Van der Does et al. 1996) correlate with lower subjective well-being in patients with diabetes. HbAlc in particular is considered to be a salient predictor of subjective well-being (Van der Does 1996), as well as a correlate with medical variables (e.g., comorbidities, physical symptoms; Gebremedhin et al. 2019; Gorst et al. 2015) and psychological functioning (e.g.,

Table 2 Total, direct, and indirect effects of diabetes duration on life satisfaction

\begin{tabular}{|c|c|c|c|c|c|c|}
\hline \multicolumn{2}{|c|}{ Total effect (path $c$ ) } & \multicolumn{2}{|c|}{ Direct effect (path $c^{\prime}$ ) } & \multicolumn{3}{|l|}{ Indirect effects $(a b)$} \\
\hline Coefficient (SE) & $t$ value & Coefficient (SE) & $t$ value & Variable & Point estimate (boot SE) & BC 95\% CI (lower, upper) \\
\hline \multirow[t]{2}{*}{$0.05(0.07)$} & \multirow[t]{2}{*}{0.68} & \multirow[t]{2}{*}{$-0.03(0.06)$} & \multirow[t]{2}{*}{-0.49} & Self-compassion (path $a_{1} b_{1}$ ) & $0.00(0.03)$ & $(-0.06,0.06)$ \\
\hline & & & & Self-coldness (path $a_{2} b_{2}$ ) & $0.08(0.04)$ & $(0.01,0.16)$ \\
\hline
\end{tabular}

SE, standard error; boot SE, bootstrap standard error; BC 95\% CI, bias-corrected bootstrap confidence intervals; lower, upper, lower and upper bounds The regression coefficients were displayed in unstandardized form. Estimates were based on 10,000 bootstrap samples. An indirect effect was considered Significant if the bootstrap confidence interval did not include zero. The significant specific indirect effect was italicized 
depression, anxiety, fatigue, diabetes distress; Hilliard et al. 2016; Van Tilburg et al. 2001). Thus, although we did not include comorbidities, we likely controlled for variance shared with $\mathrm{HbA1c}$. Despite the lack of inclusion of comorbidity as a control variable, our model accounted for $47 \%$ of the variance in life satisfaction. Nevertheless, future studies should control for comorbid conditions, such as microvascular and macrovascular complications, autoimmune disorders, or mental health problems. Also, future studies could expand the sample to include persons with T2D. In contrast with T1D, T2D depends heavily on a person's lifestyle (WHO 2016); relationships between diabetes duration, self-compassion, self-coldness, and life satisfaction may be somewhat different in this sample compared with persons with T1D (see Ventura et al. 2019).

Another limitation is that this study used a cross-sectional design. As such, we cannot be certain about the directions of the relationship between self-compassion, self-coldness, and life satisfaction. However, we prepared our model based on experimental and correlational findings indicating that selfcompassion exerts a positive influence on life satisfaction and well-being, whereas self-coldness predicts depression and anxiety (Eriksson et al. 2018; Kane et al. 2018). To infer causality, future studies should examine our study model longitudinally.

Finally, we should consider the study measures. We used a non-specific measure of self-compassion. Although this is the norm in self-compassion research, future studies may take advantage of using a newly developed tool measuring diabetes-specific self-compassion (Tanenbaum et al. 2018). In addition, we limited our investigation to a cognitivejudgmental aspect of subjective well-being. Future studies could reveal additional insights by including the affective aspect of well-being (i.e., positive and negative emotions).

Data and/or Code Availability All data are available at the Open Science Framework (https://osf.io/ngj9s/).

Author Contributions EC: conceptualized the study, performed data analyses, and wrote and revised the manuscript. DK: designed the study, assisted with data collection, and collaborated in the writing and editing of the manuscript. SD: designed and executed the study, and collaborated in the editing of the manuscript. REB: consulted on the study design and analyses, and collaborated in the writing and editing of the manuscript. All authors approved the final version of the manuscript for submission.

Funding Information This research did not receive any specific grant from funding agencies in the public, commercial, or not-for-profit sectors.

\section{Compliance with Ethical Standards}

Conflict of Interest The authors declare that they have no conflict of interest.

Ethics Approval All procedures performed in studies involving human participants were in accordance with the ethical standards of University of
Silesia in Katowice, Poland, and with the 1964 Helsinki declaration and its later amendments or comparable ethical standards.

Informed Consent Informed consent was obtained from all individual participants included in the study.

Open Access This article is licensed under a Creative Commons Attribution 4.0 International License, which permits use, sharing, adaptation, distribution and reproduction in any medium or format, as long as you give appropriate credit to the original author(s) and the source, provide a link to the Creative Commons licence, and indicate if changes were made. The images or other third party material in this article are included in the article's Creative Commons licence, unless indicated otherwise in a credit line to the material. If material is not included in the article's Creative Commons licence and your intended use is not permitted by statutory regulation or exceeds the permitted use, you will need to obtain permission directly from the copyright holder. To view a copy of this licence, visit http://creativecommons.org/licenses/by/4.0/.

\section{References}

Ahola, A. J., Saraheimo, M., Forsblom, C., Hietala, K., Sintonen, H., Groop, P. H., \& FinnDiane Study Group. (2010). Health-related quality of life in patients with type 1 diabetes - association with diabetic complications (the FinnDiane Study). Nephrology, Dialysis, Transplantation, 25(6), 1903-1908. https://doi.org/10. 1093/ndt/gfp709.

Alemzadeh, R., \& Ali, O. (2011). Diabetes mellitus. In R. M. Kliegman, B. F. Stanton, J. W. St. Geme III, N. F. Schor, \& R. E. Behrman (Eds.), Nelson textbook of pediatrics (19th ed., pp. 1968-1997). Elsevier Saunders Inc..

Altınok, A., Marakoğlu, K., \& Kargın, N. Ç. (2016). Evaluation of quality of life and depression levels in individuals with type 2 diabetes. Journal of Family Medicine and Primary Care, 5(2), 302-308. https://doi.org/10.4103/2249-4863.192358.

American Diabetes Association. (2019a). Glycemic targets: standards of medical care in diabetes-2019. Diabetes Care, 42(Supplement 1), 61-70. https://doi.org/10.2337/dc20-S006.

American Diabetes Association. (2019b). Standards of medical care in diabetes - 2019 abridged for primary care providers. Diabetes Care, 37(1), 11-34. https://doi.org/10.2337/cd18-0105.

Brenner, R. E., Heath, P. J., Vogel, D. L., \& Credé, M. (2017). Two is more valid than one: examining the factor structure of the SelfCompassion Scale (SCS). Journal of Counseling Psychology, 64(6), 696-707. https://doi.org/10.1037/cou0000211.

Brenner, R. E., Vogel, D. L., Lannin, D. G., Engel, K. E., Seidman, A. J., \& Heath, P. J. (2018). Do self-compassion and self-coldness distinctly relate to distress and well-being? A theoretical model of selfrelating. Journal of Counseling Psychology, 65(3), 346-357. https:// doi.org/10.1037/cou0000211.

Connell, C. M., Storandt, M., \& Lichty, W. (1990). Impact of health belief and diabetes-specific psychosocial context variables on selfcare behavioural, metabolic and depression in older adults with diabetes. Behaviour, Health and Aging, 1(3), 63-75.

Cunningham, A. T., Crittendon, D. R., White, N., Mills, G. D., Diaz, V., \& LaNoue, M. D. (2018). The effect of diabetes self-management education on HbAlc and quality of life in African-Americans: a systematic review and meta-analysis. BMC Health Services Research, 18, 367. https://doi.org/10.1186/s12913-018-3186-7.

Daneman, D. (2006). Type 1 diabetes. Lancet, 367(9513), 847-858. https://doi.org/10.1016/S0140-6736(06)68341-4. 
Dempster, A., Laird, N., \& Rubin, D. (1977). Maximum likelihood from incomplete data via the EM algorithm. Journal of the Royal Statistical Society. Series B (Methodological), 39(1), 1-38. https:// doi.org/10.1111/j.2517-6161.1977.tb01600.x.

Diener, E. D. (2006). Understanding scores on the Satisfaction with Life Scale. http://labs.psychology.illinois.edu/ ediener/Documents/ Understanding\%20SWLS\%20Scores.pdf

Diener, E. D., Emmons, R. A., Larsen, R. J., \& Griffin, S. (1985). The satisfaction with life scale. Journal of Personality Assessment, 49(1), 71-75. https://doi.org/10.1207/s15327752jpa4901_13.

Eriksson, T., Germundsjö, L., Åström, E., \& Rönnlund, M. (2018). Mindful self-compassion training reduces stress and burnout symptoms among practicing psychologists: a randomized controlled trial of a brief web-based intervention. Frontiers in Psychology, 9, 2340. https://doi.org/10.3389/fpsyg.2018.02340.

Ferrari, M., Dal Cin, M., \& Steele, M. (2017). Self-compassion is associated with optimum self-care behaviour, medical outcomes and psychological well-being in a cross-sectional sample of adults with diabetes. Diabetes Medicine, 34(11), 1546-1553. https://doi.org/10. $1111 / \mathrm{dme} .13451$

Friis, A. M., Consedine, N. S., \& Johnson, M. H. (2015a). Does kindness matter? Diabetes, depression, and self-compassion: a selective review and research agenda. Diabetes Spectrum: A Publication of the American Diabetes Association, 28(4), 252-257. https://doi.org/10. 2337/diaspect.28.4.252.

Friis, A. M., Johnson, M. H., Cutfield, R. G., \& Consedine, N. S. (2015b). Does kindness matter? Self-compassion buffers the negative impact of diabetes-distress on HbA1c. Diabetic Medicine, 32(12), 1634 1640. https://doi.org/10.1111/dme.12774.

Friis, A. M., Johnson, M. H., Cutfield, R. G., \& Consedine, N. S. (2016). Kindness matters: a randomized controlled trial of a mindful selfcompassion intervention improves depression, distress, and $\mathrm{HbA} 1 \mathrm{c}$ among patients with diabetes. Diabetes Care, 39(11), 1963-1971. https://doi.org/10.2337/dc16-0416.

Fritz, M. S., \& Mackinnon, D. P. (2007). Required sample size to detect the mediated effect. Psychological Science, 18(3), 233-239. https:// doi.org/10.1111/j.1467-9280.2007.01882.x.

Gable, S. L., \& Haidt, J. (2005). What (and why) is positive psychology? Review of General Psychology, 9(2), 103-110. https://doi.org/10. 1037/1089-2680.9.2.103.

Gebremedhin, T., Workicho, A., \& Angaw, D. A. (2019). Health-related quality of life and its associated factors among adult patients with type II diabetes attending Mizan Tepi University Teaching Hospital, Southwest Ethiopia. BMJ Open Diabetes Research \& Care, 7, e000577. https://doi.org/10.1136/bmjdrc-2018-000577.

Gorst, C., Kwok, C. S., Aslam, S., Buchan, I., Kontopantelis, E., Myint, P. K., Heatlie, G., Loke, Y., Rutter, M. K., \& Mamas, M. A. (2015). Long-term glycemic variability and risk of adverse outcomes: a systematic review and meta-analysis. Diabetes Care, 38(12), 2354-2369. https://doi.org/10.2337/dc15-1188.

Graue, M., Wentzel-Larsen, T., Hanestad, B. R., Båtsvik, B., \& Søvik, O. (2003). Measuring self-reported, health-related, quality of life in adolescents with type 1 diabetes using both generic and diseasespecific instruments. Acta Paediatrica, 92(10), 1190-1196. https:// doi.org/10.1111/j.1651-2227.2003.tb02483.x.

Hayes, A. F. (2013). Introduction to mediation, moderation, and conditional process analysis: a regression-based approach. Guilford Press.

Hilliard, M. E., Yi-Frazier, J. P., Hessler, D., Butler, A. M., Anderson, B. J., \& Jaser, S. (2016). Stress and A1c among people with diabetes across the lifespan. Current Diabetes Reports, 16(8), 67. https://doi. org/10.1007/s11892-016-0761-3.

Holmes-Truscott, E., Browne, J. L., Pouwer, F., Speight, J., \& Cummins, R. A. (2016). Subjective wellbeing among adults with diabetes: results from diabetes MILES-Australia. Journal of Happiness
Studies, 17(3), 1205-1217. https://doi.org/10.1007/s10902-0159638-4.

IBM Corp. (2017). IBM SPSS Statistics for Windows, Version 25.0. IBM Corp.

Juczyński, Z. (2001). Skala Satysfakcji z Życia - SWLS [the satisfaction with life scale - SWLS]. In Z. Juczyński (Ed.), Narzędzia pomiaru $w$ promocji $i$ psychologii zdrowia [measurement tools in health promotion and health psychology] (pp. 134-141). Pracownia Testów Psychologicznych PTP.

Kane, N. S., Hoogendoorn, C. J., Tanenbaum, M. L., \& Gonzalez, J. S. (2018). Physical symptom complaints, cognitive emotion regulation strategies, self-compassion and diabetes distress among adults with type 2 diabetes. Diabetic Medicine, 35(12), 1671-1677. https://doi. org/10.1111/dme.13830.

Kueh, Y. C., Morris, T., Borkoles, E., \& Shee, H. (2015). Modelling of diabetes knowledge, attitudes, self-management, and quality of life: a cross-sectional study with an Australian sample. Health and Quality of Life Outcomes, 13, 129. https://doi.org/10.1186/s12955015-0303-8.

Little, R. J. A. (1988). A test of missing completely at random for multivariate data with missing values. Journal of the American Statistical Association, 83(404), 1198-1202. https://doi.org/10. 2307/2290157.

Lloyd, C. E., \& Orchard, T. J. (1999). Physical and psychological wellbeing in adults with type 1 diabetes. Diabetes Research and Clinical Practice, 44(1), 9-19. https://doi.org/10.1016/S0168-8227(99) 00004-2.

López, A., Sanderman, R., Smink, A., Zhang, Y., van Sonderen, E., Ranchor, A., \& Schroevers, M. J. (2015). A reconsideration of the Self-Compassion Scale's total score: self-compassion versus selfcriticism. PLoS One, 10(7), e0132940. https://doi.org/10.1371/ journal.pone.0132940.

MacKinnon, D. P., Fairchild, A. J., \& Fritz, M. S. (2007). Mediation analysis. Annual Review of Psychology, 58, 593. https://doi.org/10. 1146/annurev.psych.58.110405.085542.

MacKinnon, D. P., Lockwood, C. M., \& Williams, J. (2004). Confidence limits for the indirect effect: distribution of the product and resampling methods. Multivariate Behavioral Research, 39, 99-128. https://doi.org/10.1207/s15327906mbr3901 4.

Muris, P., Otgaar, H., \& Pfattheicher, S. (2019). Stripping the forest from the rotten trees: compassionate self-responding is a way of coping, but reduced uncompassionate self-responding mainly reflects psychopathology. Mindfulness, 10(1), 196-199. https://doi.org/10. 1007/s12671-018-1030-0.

Muris, P., \& Petrocchi, N. (2017). Protection or vulnerability? A metaanalysis of the relations between the positive and negative components of self-compassion and psychopathology. Clinical Psychology \& Psychotherapy, 24(2), 373-383. https://doi.org/10.1002/cpp. 2005.

Neff, K. D. (2003a). Self-compassion: an alternative conceptualization of a healthy attitude toward oneself. Self and Identity, 2(2), 85-101. https://doi.org/10.1080/15298860309032.

Neff, K. D. (2003b). The development and validation of a scale to measure self-compassion. Self and Identity, 2(3), 223-250. https://doi. org/10.1080/15298860309027.

Neff, K. D. (2016). The Self-Compassion Scale is a valid and theoretically coherent measure of self-compassion. Mindfulness, 7(1), 264 274. https://doi.org/10.1007/s12671-015-0479-3.

Neff, K. D., \& Germer, C. K. (2013). A pilot study and randomized controlled trial of the mindful self-compassion program. Journal of Clinical Psychology, 69(1), 28-44. https://doi.org/10.1002/jclp. 21923.

Pavot, W., \& Diener, E. (2008). The satisfaction with life scale and the emerging construct of life satisfaction. The Journal of Positive Psychology, 3(2), 137-152. https://doi.org/10.1080/ 17439760701756946. 
Petterson, T., Lee, P., Hollis, S., Young, B., Newton, P., \& Dornan, T. (1998). Well-being and treatment satisfaction in older people with diabetes. Diabetes Care, 21(6), 930-935. https://doi.org/10.2337/ diacare.21.6.930.

Preacher, K. J., \& Hayes, A. F. (2008). Asymptotic and resampling strategies for assessing and comparing indirect effects in multiple mediator models. Behavior Research Methods, 40, 879-891. https://doi. org/10.3758/BRM.40.3.879.

Roy, T., \& Lloyd, C. E. (2012). Epidemiology of depression and diabetes: a systematic review. Journal of Affective Disorders, 142, 8-21. https://doi.org/10.1016/S0165-0327(12)70004-6.

Shrout, P. E., \& Bolger, N. (2002). Mediation in experimental and nonexperimental studies: new procedures and recommendations. Psychological Methods, 7(4), 422-445. https://doi.org/10.1037/ 1082-989X.7.4.422.

Sirois, F. M., Molnar, D. S., \& Hirsch, J. K. (2015). Self-compassion, stress, and coping in the context of chronic illness. Self and Identity, 14(3), 334-347. https://doi.org/10.1080/15298868.2014.996249.

Sparring, V., Nyström, L., Wahlström, R., Jonsson, P. M., Östman, J., \& Burström, K. (2013). Diabetes duration and health-related quality of life in individuals with onset of diabetes in the age group 15-34 years - a Swedish population-based study using EQ-5D. BMC Public Health, 13, 377. https://doi.org/10.1186/1471-2458-13-377.

Stahl-Pehe, A., Landwehr, S., Lange, K. S., Bächle, C., Castillo, K., Yossa, R., Lüdtke, J., Holl, R. W., \& Rosenbauer, J. (2017). Impact of quality of life (QoL) on glycemic control (HbAlc) among adolescents and emerging adults with long-duration type 1 diabetes: a prospective cohort-study. Pediatric Diabetes, 18(8), 808-816. https://doi.org/10.1111/pedi.12487.

Tanenbaum, M. L., Adams, R. N., Gonzalez, J. S., Hanes, S. J., \& Hood, K. K. (2018). Adapting and validating a measure of diabetesspecific self-compassion. Journal of Diabetes and its
Complications, 32(2), 196-202. https://doi.org/10.1016/j.jdiacomp. 2017.10.009.

Van der Does, F. E., De Neeling, J. N., Snoek, F. J., Kostense, P. J., Grootenhuis, P. A., Bouter, L. M., \& Heine, R. J. (1996). Symptoms and well-being in relation to glycemic control in type II diabetes. Diabetes Care, 19(3), 204-210. https://doi.org/10.2337/ diacare.19.3.204

Van Tilburg, M. A., McCaskill, C. C., Lane, J. D., Edwards, C. L., Bethel, A., Feinglos, M. N., \& Surwit, R. S. (2001). Depressed mood is a factor in glycemic control in type 1 diabetes. Psychosomatic Medicine, 63(4), 551-555. https://doi.org/10.1097/00006842200107000-00005.

Ventura, A. D., Nefs, G., Browne, J. L., Friis, A. M., Pouwer, F., \& Speight, J. (2019). Is self-compassion related to behavioural, clinical and emotional outcomes in adults with diabetes? Results from the second diabetes MILES - Australia (MILES-2) study. Mindfulness, 10(7), 1222-1231. https://doi.org/10.1007/s12671-018-1067-0.

Vermeulen-Smit, E., Mares, S. H., Verdurmen, J. E., Van der Vorst, H., Schulten, I. G., Engels, R. C., \& Vollebergh, W. A. (2014). Mediation and moderation effects of an in-home family intervention: the "In Control: No Alcohol!" pilot study. Prevention Science, 15(5), 633-642. https://doi.org/10.1007/s11121-013-0424-4.

World Health Organization. (2016). Global report on diabetes. World Health Organization https://apps.who.int/iris/handle/10665/204871.

Zessin, U., Dickhäuser, O., \& Garbade, S. (2015). The relationship between self-compassion and well-being: a meta-analysis. Applied Psychology. Health and Well-Being, 7(3), 340-364. https://doi. org/10.1111/aphw.12051.

Publisher's Note Springer Nature remains neutral with regard to jurisdictional claims in published maps and institutional affiliations. 